Journal of Money and Economy

Vol. 16, No. 2, Spring 2021

pp. 253-282

DOI: $10.29252 /$ jme.16.2.253

Original Research Article

\title{
Outperformance Testing of a Dynamic Assets Portfolio Selection Supplemented with a Continuous Paths Levy Process
}

\section{Mohammad Feghhi Kashani*}

Ahmadreza Mohebimajd ${ }^{\dagger}$

Approved: 30 Jan 2022

This study aims at getting a better performance for optimal stock portfolios by modeling stocks prices dynamics through a continuous paths Levy process. To this end, the share prices are simulated using a multi-dimensional geometric Brownian motion model. Then, we use the results to form the optimal portfolio by maximizing the Sharpe ratio and comparing the findings with the outputs of the conventional model. To examine the robustness of the results, we have evaluated its performance for different investment horizons and various volumes of price information over a long period (approximately twenty years) in the Tehran Stock Exchange (TSE). Findings indicate that within the trading dates spanning the interval 24-Mar-2001 to 19-Sep-2020, the return of the portfolios obtained from applying this simulation scheme for maximization of Sharpe ratio is (244\% on average) higher and their risk (standard deviation) are lower (1227\% on average) than those realized by the conventional methods. Additionally, a comparison of the simulation approach with a performance of the actual market portfolios indicates that the Sharpe ratios of the simulation method are higher $(0.055 \%$ on average) than those resulting from the total market performances. The results of the stochastic dominance test show that our proposed strategy has a first-order stochastic dominance (FSD) over the conventional one and market portfolios, that means at each level of cumulative distribution, the Sharpe ratio of our method is higher, and as FSD test makes no assumptions about the curvature of investors' utility functions, these results do not depend on the degree of risk aversion of investors, and as long as investors prefer a higher Sharpe ratio, they would be better off if they follow our proposed strategy.

Keywords: Portfolio, Multidimensional Geometric Brownian Motion, Sharpe Ratio, Mean-Variance, Stochastic Dominance

JEL Classification: C61, C63, G11, G17.

\footnotetext{
Department of Economics, Allameh Tabataba'i University, Tehran, Iran; mir30kas@gmail.com

$\dagger$ Department of Economics, Allameh Tabataba'i University, Tehran, Iran; A.MohebiMajd@1se.ac.uk (Corresponding Author)
} 


\section{Introduction}

The optimal portfolio selection theory has always been one of the main concerns in financial economics. Two alternatives within this approach are AKA modern portfolio theory (Mean-Variance Method) (Markowitz, 1952 \& 1959), and the Sharpe ratio maximization (Sharpe, $1966 \& 1994$ ), which routinely use raw stock return data to obtain the optimal portfolio. The Sharpe ratio maximization fail to notice the stochastic behavior of stock prices that was first detected by Bachelor (1900) (Mwamba \& Mwambi, 2010). To overcome this shortcoming, one can refer to the prominent study Black and Scholes (Black \& Scholes, 1973), which used Geometric Brownian Motion (GBM). In this study, using a Multi-dimensional Geometric Brownian Motion (MGBM) process, we first simulate market share prices to include the random and non-random behavior of stock prices, then use the results in the meanvariance and the Sharpe ratio maximization methods. Our method considers the covariance of each share price with the other market shares and allows us to study the stock prices as the ever-positive variables.

The mean-variance method would offer numerous portfolios at any time, ranging from risk-free to maximum risk portfolios. As a result, a single portfolio is not necessarily determined as the optimal one. Thus, one needs a criterion to single out among many. The Sharpe ratio, defined as the excess return relative to a risk-free asset per unit of risk, is a conventional criterion for choosing the optimal stocks portfolio. Where this ratio is maximum, we will have only one portfolio. So, we consider the Sharpe ratio as the criterion for selecting the optimal portfolio. Though market researchers and analysts have tried many alternative models to investigate the performance of stock portfolios, the Sharpe ratio is still one of the most popular ratios in ranking portfolios (Kourtis, 2016). So, in this paper, we focus on the Sharpe ratio.

To our best knowledge, this way of approaching the issue is new. One of the approaches similar to our work is Merton's portfolio model (Merton, 1971), which selects the optimal intertemporal portfolio of stock(s) and bond (as a riskless asset) by maximizing the expected utility. This model usually uses a GBM or MGBM to simulate risky assets (stocks). (Weiner, 2004; Lakner \& Ma Nygren, 2006; Chellathurai \& Draviam, 2007; Back, 2010; Buckley, Brown \& Marshall, 2012; Castellano \& Cerqueti, 2012; Tourin \& Yan, 2013; Pun \& Wong, 2016; Biagini \& Pınar, 2017; Mariani, Recchioni \& Ciommi, 2019;).

Another group of studies on the Markowitz mean-variance problem uses the GBM to simulate stock prices (Xie, 2009; Muteba Mwamba \& Suteni, 
2010; Spinu, 2015; Abensur, Moreira \& De Faria, 2020). The other group uses MGBM to model stock prices. But in the numerical solution of the model, they use one stock that converts the model to GBM (Xie, Li \& Wang, 2008; Zeng \& Li 2011; Wei \& Wang, 2017). Yunita et al. (2015) does the same thing but uses three stocks in the model simulation. Pedersen and Peskir (2017) study the dynamics of a nonlinear mean-variance optimal control problem that uses the MGBM model to model risky stock prices. Dmitrašinović and Ware (2006) and Gambrah and Pirvu (2014) tried to improve the performance of portfolios focusing only on different risk measures. In their models, share prices follow MGBM, too. Chen et al. (2021) focus on the shortcoming of the mean-variance model, predicts stocks prices by a hybrid model based on machine learning, then selects stocks with higher potential returns for meanvariance portfolio optimization.

The rest of the paper has been structured as follows: Section 2 provides a brief overview of the pursued methodology and its background. Section 3 outlines the employed data and major characteristics of the TSE. Section 4 presents the results and their distinct features. Section 5 concludes.

\section{The Methodology \& Background}

The optimal stock portfolio detection regularly involves using equity data in its raw format (Kim, Kim \& Fabozzi, 2015). Instead, this paper offers a simulation of share prices by the MGBM process and then uses the results to obtain the Sharpe-ratio maximizing portfolio. Next, the resulting portfolio will be compared with those from the conventional method.

\subsection{Multi-dimensional Geometric Brownian Motion}

To simulate the price of market shares, we use multi-dimensional geometric Brownian motion, in which case the correlation between the returns of all shares is considered in the simulation. For this purpose, we consider the following stochastic differential equations system

$d X_{t}=\mu_{t} X_{t} d t+A\left(X_{t}\right) \Sigma_{t} d B_{t}$

Where $d X_{t}, \mu_{t}, X_{t}, A\left(X_{t}\right), \Sigma_{t}$ and $B_{t}$ are respectively $n \times 1$ vector of the differential processes, $n \times n$ matrix of expected returns (the drift parameter), $n \times 1$ state vector of the random process variables, a square matrix of order $n$ whose primary diagonal values are the same as the elements of the $X_{t}$ and the other values are zero, a square matrix of order $n$ that the primary diagonal values are standard deviation of the random variables and other off-diagonal 
elements represent the covariance between the variables, and $n \times 1$ vector of one-dimensional independent Brownian motion. To solve the system (1), we need Ito's formula. For simplicity, we show the solution of one process; other processes follow the same approach.

\subsection{Ito's Formula}

If $X_{i t}$ is an Ito process such that $d X_{i t}=\mu_{i} X_{i t} d t+X_{i t} \sum_{j=1}^{n} \sigma_{i j} d B_{j t}$ and $f: R^{2} \rightarrow R$ is a twice continuously differentiable function, then $Y_{i t}=f\left(X_{i t}\right)$ is also an Ito process, and we have

$d Y_{i t}=f_{x}\left(X_{i t}\right) d X_{i t}+\frac{1}{2} f_{x x}\left(X_{i t}\right)\left(d X_{i t}\right)^{2}$

If $Y_{i t}=\ln X_{i t}$, using the stochastic differential equations system (1) and Ito's formula for $i \in[1, n]$ we have

$X_{i t}=X_{i 0} \exp \left[\left(\mu_{i}-\frac{1}{2} \sum_{j=1}^{n} \sigma_{i j}^{2}\right) t+\sum_{j=1}^{n} \sigma_{i j} B_{j t}\right]$

Equation (3) defines $X_{i t}$ as a geometric Brownian motion process (Duffie, 2001) (Glasserman, 2013).

\subsection{Portfolio Optimization}

This section explains how an investor builds the optimal stock portfolio by maximizing the Sharpe ratio. To form the Sharpe ratio problem, we use Back (2010) assumptions and settings: Our market is composed of $\mathbf{n}$ stocks (risky assets $)^{1}, r_{i}$ is the return on stock $i$ at time $t$ and $\bar{r}>0$ represents the return on riskless asset. $R, E[R], \Sigma$ and $I$ are respectively n-dimensional vector with $r_{i}$ as its $i$ th element, vector of the expected returns, $n \times n$ nonsingular covariance matrix, and n-dimensional column vector of ones. Since $\Sigma$ is nonsingular, all possible portfolios are risky. $\omega^{\prime} R$ is the portfolio's return, where $\omega$ is the portfolio's vector of assets' weights. $\omega^{\prime} \mu$ and $\omega^{\prime} \Sigma \omega$ are respectively mean and variance of the portfolio's return.

We further assume $I^{\prime} \omega=1$ which guarantees that the portfolio consists of only risky assets. In addition, we assume that we have a possible portfolio $\omega^{*}$

\footnotetext{
${ }^{1}$ These risky assets are in fact the stocks and risk-free asset is bank deposits.
} 
such that $\mu \omega^{*}>\bar{r}$ (Back, 2010). ${ }^{1}$ To obtain the maximum Sharpe ratio at time $\mathrm{t}$, we solve the following problem:

$\max \frac{\omega^{T} \mu-\bar{r}}{\sqrt{\omega^{\prime} \Sigma \omega}}$

s.t. $\quad I^{\prime} \omega=1$

$\mu^{\prime} \omega^{*}>\bar{r}$

The numerator and denominator of the function represent the average portfolio return (above the return on the risk-free asset) and the standard deviation of the portfolio's returns, respectively. We consider the standard deviation of the portfolio's return as a measure of risk. This ratio indicates the rate of return on the portfolio per unit of risk, so the higher the ratio, the better the portfolio performance (Kourtis, 2016).

To solve the problem (4), we use the constrained quadratic programming method, which is a subset of the nonlinear programming method. The quadratic programming method minimizes the objective function, so it is necessary to first turn the Sharpe ratio maximization problem into the following minimization problem. ${ }^{2}$

$\min \quad \gamma^{\prime} \Sigma \gamma$

s. t. $\tau>0,(\gamma, \tau) \in H^{+}$

s.t. $\quad \tau>0,(\gamma, \tau) \in H^{+}$

$(\mu-\bar{r} I)^{\prime} \gamma=1$

Where, $\tau=\frac{1}{(\mu-\bar{r} I)^{\prime} \omega}$ and $\gamma=\tau \omega$ (Cornuejols \& Tütüncü, 2006).

\section{The Data}

All available data on the price of active symbols in the Tehran Stock Exchange within the trading dates spanning the interval 24-Mar-2001 to 19-Sep-2020 were used to conduct the study. Some symbols, such as mutual funds and government securities, were removed from the analysis due to differences in risk and return from other symbols. Some other symbols that cannot be invested in, such as market indicators and test symbols, were removed from

\footnotetext{
${ }^{1}$ To solve the Sharpe ratio maximization problem with a convex quadratic programming problem, we need these two assumptions.

${ }^{2}$ Proof of it and the quadratic programming method to solve this problem are available upon request from the authors.
} 
the list. After this refinement, 808 symbols remained. In addition, some companies have old and new symbols, which increases the number of symbols compared to the actual number of active companies. The method used in this research, which is described in the missing data section, will lead to the use of the original data and the removal of additional symbols. ${ }^{1}$

There are missing data in the time series of stock prices due to two main ins and outs. First, the period under study from 24-Mar-2001 onwards is considered the longest period available, and many companies have been listed in the capital market after this date. Thus there is no data before their arrival time. Second, sometimes corporate symbols are temporarily closed during their operation for various reasons, including holding extraordinary general meetings for taking key decisions.

There are several ways to manage missing data, including removing or estimating data. In the removal method, at each time, if the prices of all shares are available, we preserve data. Using this method causes a large amount of lost information and extracts an unrealistic portfolio. Another common method is to estimate the mean and covariance of stock returns in terms of missing data. This method is based on two strong assumptions. According to the first assumption, each observation is generated based on a multivariate normal distribution, and according to the second assumption, the data are lost randomly. We should use this method when it is not possible to estimate the mean and covariance of stock returns, and it is necessary to test the above assumptions beforehand. We employ another method that allows the estimation of mean and covariance; thus, do not need to utilize the estimation method.

Since we are looking to evaluate the model's predictive power, we assume that the investor stands at the beginning of period $t$ and wants to use the information of the last L days to obtain an optimal portfolio, then buy these shares at period $t$. As a result, the investor's criterion is the availability of price data for the shares in a significant number of last $\mathrm{L}$ days as well as at the beginning of period (t). Shares that have lost more than 25 percent of their observations in the last $\mathrm{L}$ days or are not available at time $\mathrm{t}$ (have missing data) will be removed from the list. For each share, initially, we fill missing prices with the previous non-missing value, then with the next non-missing value. Using this method, we consider zero returns for trading suspensions that correspond to reality. In this way, we will not have two issues of other

\footnotetext{
${ }^{1}$ More details about the data set, its characteristics and the list of symbols are available upon request from the authors.
} 
methods, i.e., losing information and estimation of unrealistic mean and covariance. There are five price data per share (open, last, close, highest, and lowest). Because the closing price determines the return on a stock at the end of the trading day, and over a period, we use the closing price as the criterion for calculating the return. Given the number of available periods is 4240 trading days for 19.5 years, on average, every 18 trading days is considered a month. The investor's strategy can be summarized as follows: the investor uses the price data of, say, the last 216 market days (one calendar year) to estimate and purchase an optimal stock portfolio and holds the purchased shares for 18 market days ( 1 calendar month), then at the end of the month, again uses the price data of the previous year to estimate and purchase the portfolio and repeats this process until the last period.

We assume that at the beginning of each period, investors sell the previous portfolio and purchase a new one, so to calculate the profit of each method, the stock trading commission will be deducted from it. Before the implementation of the new law on July 22, 2020, the transaction fee was equal to 1.43 percent, and after that, it was reduced to 1.25 percent.

In general, considering the securities market investing strategies, there are two common approaches. The first one is the buy-and-hold approach, in which the portfolio is purchased at the beginning of the investment period and upheld until the end. In the second approach, the portfolio is purchased and invested for a certain period, and at the end of the period, a new portfolio is constructed for investment in the next period. In our method, which exploits the second approach, we use the information of $L$ previous days at $t=s . s+f . s+$ $2 f . \cdots . T$ (witch $t=s$ is the beginning of first investment horizon and $f$ is the length of each investment period) while in the buy and hold approach, we only use the available information of $L$ previous days at the time $t=s$ (beginning of investment horizon). So, the great difference and importance of our assumption compared to the other one is that at the end of the previous investment period (and the beginning of the next period), new information (the previous day) is used to construct the optimal portfolio.

One of the key variables is the risk-free interest rate, for which we consider the annual interest rate on the one-year investment deposits in the banking system. We got the data from the Central Bank of Iran. Then we convert this rate to the daily rate using the following formula: 
$D R=\left(1+\frac{A R}{100}\right)^{1 / 216}-1$

$A R$ and $D R$ are the annual and daily interest rates on the investment deposits, respectively. Moreover, we have 216 trading days a year.

\section{Empirical Results}

As mentioned earlier, the conventional method of extracting the optimal stock portfolio uses raw price data to estimate the mean and covariance of returns, estimate the efficient boundary, and maximize the Sharpe ratio. This study proposes to simulate the stock price data using an MBGM model, then we utilize the simulated data to determine the optimal portfolio through the Sharpe ratio maximization. To evaluate the performance of this method compared to the conventional method, the predictive power of the two methods in terms of mean and variance has been compared with each other. the method of this paper (using the simulated data) and the ordinary method (using the raw data) hereafter referred to the simulation method and is called the conventional method respectively.

\subsection{Comparing the Efficient Frontier of the Two Methods}

To clarify the results of the two methods, Figure (1) plots the efficient frontier of the conventional method (with black mesh lines) and the simulation method (without black mesh lines) for about 18 years (from December 2002 to September 2020) at 18-days intervals. ${ }^{1}$ The outputs are based on the investors' beginning-period price information set for the last 378 days. Also, the results reflect one implementation of the method at each period. We have ended up with 20 optimal investment portfolios for each method at any run.

\footnotetext{
${ }^{1}$ Note that for greater clarity these charts are provided for a random lot only. See Appendix for the efficient boundary of the two methods separately.
} 


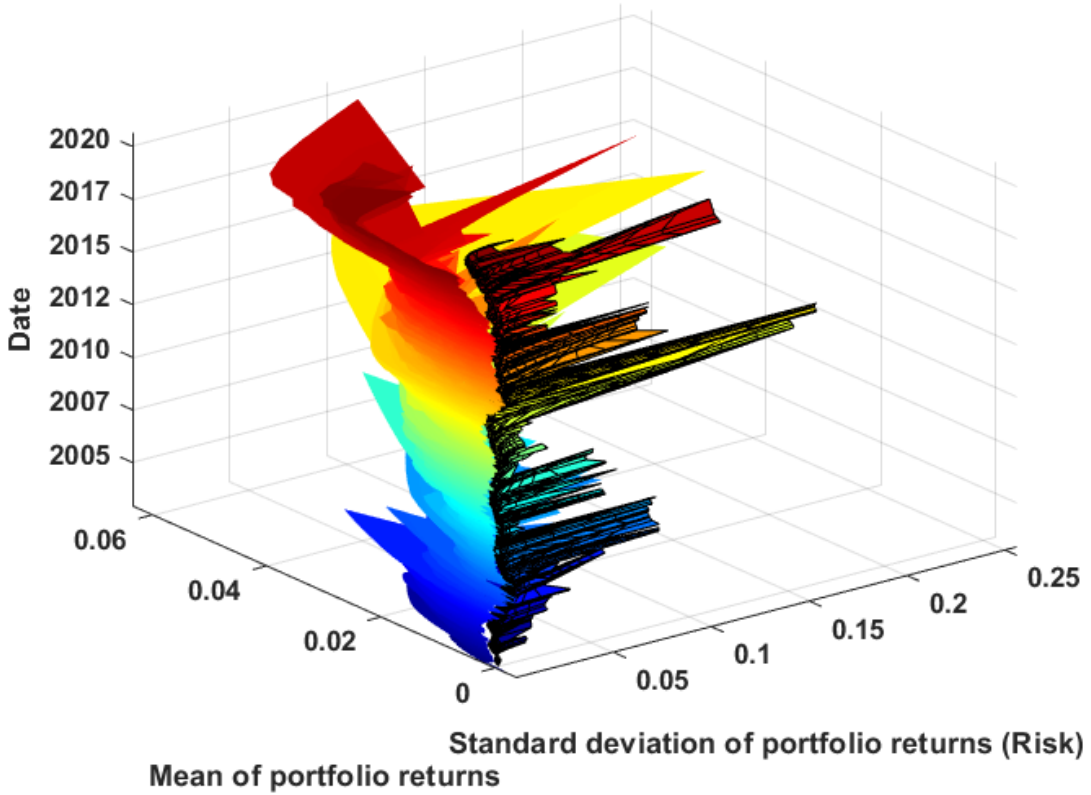

Figure 1. Mean-Variance Efficient Frontier of Conventional Method (with Black Mesh Lines) and Simulation Method (without Black Mesh Lines) for 18-Year Period (December 2002 to September 2020) at 1-Month Intervals (18 Trading Days).

Source: Research findings

Figure (2) shows a bivariate histogram of conventional (green) and simulation (blue) methods. ${ }^{1}$ This diagram illustrates the frequency of efficient frontier points. That is, we have looked into 18 years (from December 2002 to September 2020) with one-month intervals (18 trading days), and at the beginning of each period, price information of the last 378 days has been used. Each period took account of 200 optimal portfolios. Overall, we kept in check 43,000 optimal portfolios for each method.

\footnotetext{
${ }^{1}$ See Appendix to view the histogram of the two methods separately.
} 


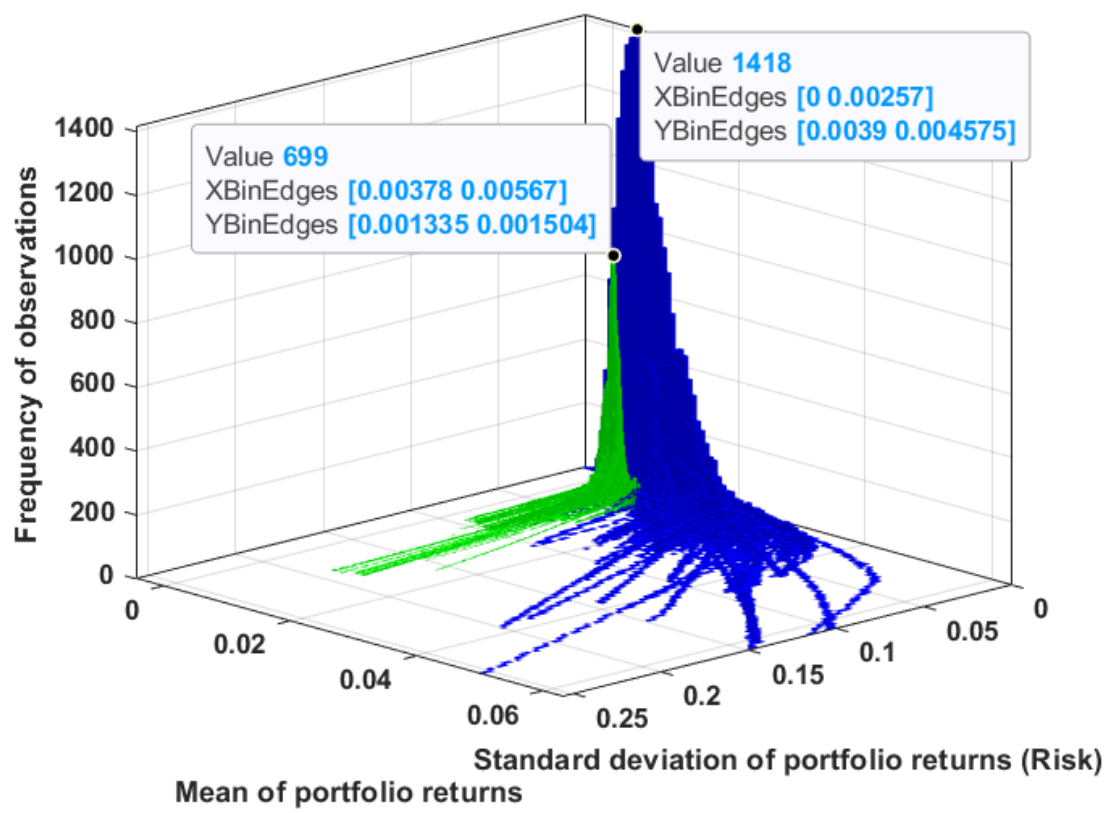

Figure 2. Bivariate Histogram of Conventional (Green) and Simulation (Blue) Methods for 18-Year Period (December 2002 to September 2020) at 1-Month Intervals (18 Trading Days).

Source: Research findings

\subsection{Comparing Performance of the Two Methods and the Actual Market Portfolio}

To evaluate the performance of the two methods, we assume that the investor stands at the beginning of time $t$ and, using price information of last $L$ days, extracts two optimal portfolios by conventional and simulation methods. Then, the investor buys these portfolios and keeps them for the next $f$ days. On the day $t+f$, we survey the performance of these portfolios. In the next period, which is the beginning of the $t+f$, again, it re-extracts the optimal portfolio using price information of last $L$ days and keeps it for next $f$ days, and at the end, we survey the performance of these portfolios. It is repeated until the last possible period. Here, to show the robustness of the results, we report the model outputs for different values of $L$ and $f$. For this purpose, we chose three values, 54 days ( 3 months), 108 days ( 6 months) and 216 days (1 year) for $f$ and three values, 540 days (2.5 years), 1080 days (5 years) and 2160 days (10 years) for $L$. 
First, we consider $f$ equal to 216 market days ( 1 calendar year) and report the results of the two methods for different values of $L$. Since the simulation method is based on multi-dimensional geometric Brownian motion, a vector of random variables is generated to produce the Brownian motion vector in each simulation, so the simulation results depend on the generated random vector. For this reason, to evaluate the robustness of the results, for each $L$ and $f$, we simulated 1000 times the stock prices by the multi-dimensional geometric Brownian motion method then extracted the optimal stock portfolio using Sharpe ratio maximization.

In addition to these two methods, we examine the performance of the market. The weight of each symbol in the market portfolio is the market capitalization of each symbol to the total market capitalization of the whole market (808 symbols studied). ${ }^{1}$ We assume that the investor obtains the average weights of last $L$ and $f$ days as well as the weights of the investment day to constitute the market portfolio and buys these three portfolios at the time $t$ and maintains them for next $f$ days, and this process will be repeated until the last possible period. In this way, the performance of the market portfolios can be obtained, which is the outcome of the activity of the whole market.

Table 1 reports the investment results of two methods and portfolios offered by the market. For different values $L$, the sum of the portfolios' returns of the simulation method is significantly higher than the conventional method (results of the simulation methods are the average of 1000 times simulations). Also, the sum of the standard deviation of the portfolios' returns of the simulation method for different values $L$ is less than the conventional method, which means investing with the simulation method is less risky. The best result of the conventional method in terms of return is $30 \%$ for $\mathrm{L}=1080$ and the simulation method $185 \%$ for $\mathrm{L}=2160$. In addition, the best result of the conventional method in terms of the sum of standard deviation is $3957 \%$ for $\mathrm{L}=1080$ and the simulation method $2310 \%$ for $\mathrm{L}=2160$.

Also, the average Sharpe ratios ${ }^{2}$ of the simulation method for all $L$ values are higher than the Sharpe ratios of other methods and the market portfolios, which shows that, on average, the simulation method is superior to the

\footnotetext{
${ }^{1}$ We define the market capitalization of a company as the total company's outstanding shares times the current close price of a single share.

${ }^{2}$ To derive this criterion, first, in each f-days investment period we have calculated the optimal portfolio's Sharpe ratio, then, the average ratio of all periods has been obtained. Using this method, we have only one Sharpe ratio for the conventional method, but 1000 ratios for the simulation method. The tables show the latter's average.
} 
conventional method and the market portfolios in terms of return per unit of risk. According to Sharpe ratio, the best performance of the conventional method is 0.0108 for $\mathrm{L}=2160$, the best performance of the simulation method is 0.0557 for $\mathrm{L}=2160$ and the best performance of market portfolios is 0.0446 . To evaluate the performance of conventional and simulation methods in all investment periods, the number of periods in which the Sharpe ratio of the simulation method has been higher than the conventional method is reported as a percentage of the total number of investment periods in Table I. This percentage is always more than $68 \%$ for different values $L$, which means the Sharpe ratio of the simulation method is better than the conventional method.

Table 1

Performance of the Two Methods for $f=216$

\begin{tabular}{|c|c|c|c|}
\hline Last $L$ days used to form the portfolio & $\begin{array}{c}540 \\
(2.5 \text { years }) \\
\end{array}$ & $\begin{array}{c}1080 \\
(5 \text { years })\end{array}$ & $\begin{array}{c}2160 \\
(10 \text { years })\end{array}$ \\
\hline \multicolumn{4}{|c|}{ Sum of the portfolios' returns (\%) } \\
\hline the Conventional method & -209.98 & 30.31 & 3.4 \\
\hline $\begin{array}{l}\text { the Simulation method - average of } 1000 \text { times } \\
\text { simulations }\end{array}$ & 30.39 & 165.81 & 185.95 \\
\hline \multicolumn{4}{|c|}{ Sum of standard deviation of the portfolios' returns (\%) } \\
\hline the Conventional method & 4757.4 & 3957.5 & 4238.4 \\
\hline $\begin{array}{l}\text { the Simulation method - average of } 1000 \text { times } \\
\text { simulations }\end{array}$ & 3645.6 & 2949.1 & 2310.4 \\
\hline \multicolumn{4}{|l|}{$\begin{array}{ll} & \text { Sharpe ratios } \\
\end{array}$} \\
\hline the Conventional method & -0.0371 & -0.0123 & 0.0108 \\
\hline $\begin{array}{l}\text { the Simulation method - average of } 1000 \text { times } \\
\text { simulations }\end{array}$ & 0.0105 & 0.0244 & 0.0557 \\
\hline The Market portfolio - using last $L$ Days info. & -0.0307 & 0.0072 & 0.0446 \\
\hline The Market portfolio - using last $f$ Days info. & -0.0354 & -0.0004 & 0.0189 \\
\hline The Market portfolio - using investment day info. & -0.0324 & 0.011 & 0.0216 \\
\hline Outperformed periods for the simulation method (\%) & 68.47 & 72.83 & 71.91 \\
\hline
\end{tabular}

Source: Research findings

Figure (3) compares the simulation results of MGBM and the conventional methods for all 1000 simulation trials and $\mathrm{F}=216$. In all 1000 times simulations, the sum of portfolios' returns, the sum of standard deviations, and the average of Sharpe ratios of the simulation method are more, less, and more than the conventional method, respectively, which indicates the superiority of the simulation method over the conventional method. In addition, in each simulation, the number of periods that the simulation method outperformed based on Sharpe ratios is shown as a percentage of the total investment periods, which is 998 out of 1000 simulation periods, this measure is above $50 \%$, which indicates The simulation method is more efficient than the 
conventional method. The simulation method also outperforms the other Ls and $f$ s. $^{1}$
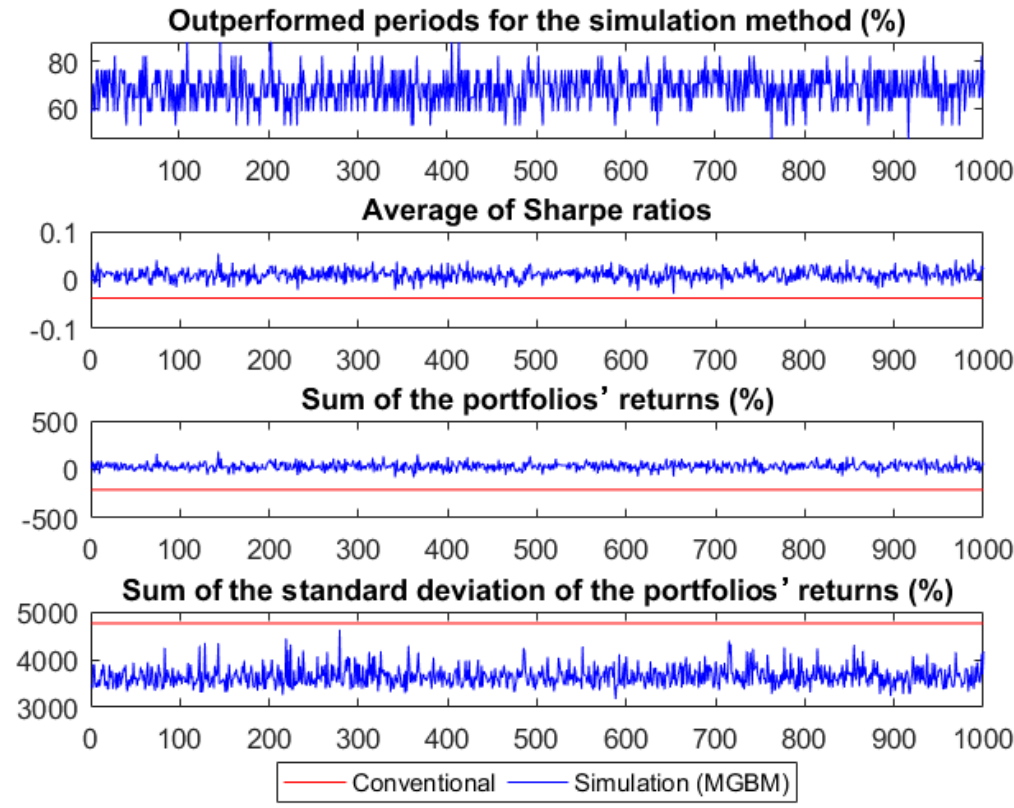

Figure 3. The Performance of Simulation (MGBM) and Conventional Methods for All 1000 Simulation Trials, $\mathrm{L}=540$ and $\mathrm{f}=216$.

Source: Research findings

Table 2 reports the results for $f=108$ and different values of $L$. According to these results, the sum of portfolios' returns and the sum of standard deviation of portfolios' returns of the simulation method are respectively more and less than those of the conventional method. The best result in terms of returns for the conventional method is $19.4 \%$ with $\mathrm{L}=2160$ and the simulation method (on average) is $298.5 \%$ with $\mathrm{L}=2160$. Moreover, the best result in terms of standard deviation for the conventional method is $4108 \%$ with $\mathrm{L}=2160$ and the simulation method (on average) $2404 \%$ with $\mathrm{L}=2160$. Based on the Sharpe ratio, the simulation method performed better in all cases, and the best Sharpe ratio for the conventional and simulation methods are 0.0308 and 0.0898 for $\mathrm{L}=2160$, and for the market portfolio, it is 0.076. Also, the percentage of periods for which the simulation method has

\footnotetext{
${ }^{1}$ See Appendix for detailed simulations results for other Ls and fs.
} 
performed better in terms of Sharpe ratio for all values is above $70 \%$. This outperformance is best achieved for $\mathrm{L}=2160$ in $75 \%$ of periods.

Table 2

Performance of the Two Methods for $f=108$

\begin{tabular}{|c|c|c|c|}
\hline Last $L$ days used to form the portfolio & $\begin{array}{c}540 \\
(2.5 \text { years }) \\
\end{array}$ & $\begin{array}{c}1080 \\
(5 \text { years })\end{array}$ & $\begin{array}{c}2160 \\
(10 \text { years })\end{array}$ \\
\hline \multicolumn{4}{|c|}{ Sum of the portfolios' returns $(\%)$} \\
\hline the Conventional method & -22.32 & 6.25 & 19.48 \\
\hline $\begin{array}{l}\text { the Simulation method - average of } 1000 \text { times } \\
\text { simulations }\end{array}$ & 238.69 & 271.5 & 298.58 \\
\hline \multicolumn{4}{|c|}{ Sum of standard deviation of the portfolios' returns $(\%)$} \\
\hline the Conventional method & 4880.8 & 3359 & 4108.5 \\
\hline $\begin{array}{l}\text { the Simulation method - average of } 1000 \text { times } \\
\text { simulations }\end{array}$ & 3709.9 & 3015.2 & 2404.6 \\
\hline \multicolumn{4}{|c|}{ Sharpe ratios } \\
\hline the Conventional method & -0.0102 & -0.0123 & 0.0308 \\
\hline $\begin{array}{l}\text { the Simulation method - average of } 1000 \text { times } \\
\text { simulations }\end{array}$ & 0.0476 & 0.0557 & 0.0898 \\
\hline The Market portfolio - using last $L$ Days info. & 0.0019 & 0.0347 & 0.076 \\
\hline The Market portfolio - using last $f$ Days info. & 0.0033 & 0.0331 & 0.0511 \\
\hline The Market portfolio - using investment day info. & 0.0063 & 0.0368 & 0.051 \\
\hline Outperformed periods for the simulation method (\%) & 70.49 & 75.12 & 71.02 \\
\hline
\end{tabular}

Source: Research findings

Table 3 reports the performance of the two methods for $\mathrm{f}=54$ and different values of L. Sum of portfolios' returns, the sum of standard deviation of portfolios' returns, and the Sharpe ratios of the simulation method are respectively more, less, and more than those of the conventional method. In addition, with increasing the last days' data to estimate the portfolio, the sum of returns and the sum of standard deviation in both methods increased and decreased, respectively. The best efficiency for the conventional method is the total return of $45 \%$ with $\mathrm{L}=2160$ and for the simulation method $290 \%$ with $\mathrm{L}=2160$. Furthermore, the best result in terms of standard deviation for the conventional method is $3688 \%$ with and for the simulation method, $2297 \%$ with $\mathrm{L}=2160$. The best Sharpe ratio for the conventional method is 0.0458 with $\mathrm{L}=216$, for the simulation method 0.0921 with $\mathrm{L}=2160$, and for the market portfolio, it is 0.0595 . Sharpe ratio of the simulation method is superior in all cases. 
Table 3

The Performance of the Two Methods for $f=54$

\begin{tabular}{|c|c|c|c|}
\hline Last $L$ days used to form the portfolio & $\begin{array}{c}540 \\
(2.5 \text { years }) \\
\end{array}$ & $\begin{array}{c}1080 \\
(5 \text { years })\end{array}$ & $\begin{array}{c}2160 \\
\text { (10 years) }\end{array}$ \\
\hline \multicolumn{4}{|c|}{ Sum of the portfolios' returns (\%) } \\
\hline the Conventional method & -82.87 & -16.2 & 45.15 \\
\hline $\begin{array}{l}\text { the Simulation method - average of } 1000 \text { times } \\
\text { simulations }\end{array}$ & 237.28 & 254.91 & 290.48 \\
\hline \multicolumn{4}{|c|}{ Sum of standard deviation of the portfolios' returns (\%) } \\
\hline the Conventional method & 4439.44 & 4222.57 & 3688.17 \\
\hline $\begin{array}{l}\text { the Simulation method - average of } 1000 \text { times } \\
\text { simulations }\end{array}$ & 3420.96 & 2852.91 & 2297.1 \\
\hline \multicolumn{4}{|c|}{ Sharpe ratios } \\
\hline the Conventional method & -0.005 & 0.0065 & 0.0458 \\
\hline $\begin{array}{l}\text { the Simulation method - average of } 1000 \text { times } \\
\text { simulations }\end{array}$ & 0.0688 & 0.0669 & 0.0921 \\
\hline The Market portfolio - using last $L$ Days info. & -0.0079 & 0.0178 & 0.0595 \\
\hline The Market portfolio - using last $f$ Days info. & -0.0016 & 0.0288 & 0.0422 \\
\hline The Market portfolio - using investment day info. & -0.0013 & 0.0278 & 0.0387 \\
\hline $\begin{array}{l}\text { Outperformed periods for the simulation method } \\
(\%)\end{array}$ & 63.64 & 63.8 & 59.29 \\
\hline
\end{tabular}

Source: Research findings

To study the difference between the two methods over time in terms of returns' mean, risk, and Sharpe ratio, we obtained optimization results for $\mathrm{L}=540$ andf $=18$. The selection of these two numbers makes it possible to evaluate the performance of the two methods with monthly accuracy in a longterm period. For this purpose, we first calculate the difference in returns of the two methods in each one month (returns of the simulation method minus returns of the conventional method), then accumulate these differences. ${ }^{1}$ Thus, the more this measure increases over time that indicates the greater the advantage of the simulation method over the conventional method. As presented in Figure (4), in 205 months (from October 2003 to September 2020), this measure has always been positive, which indicates the advantage of the simulation method over the conventional method. In addition, this criterion has had an upward trend despite various fluctuations throughout the period, which indicates an increase in the advantage of the simulation method.

\footnotetext{
${ }^{1}$ In other words, the accumulated return per month is equal to the sum of the returns of all months up to the month under review, which includes the month under review. Considering that 1000 times simulation has been done for the simulation method in each 18-days period, for each period the average return of this 1000 times has been calculated as the return of the simulation method.
} 


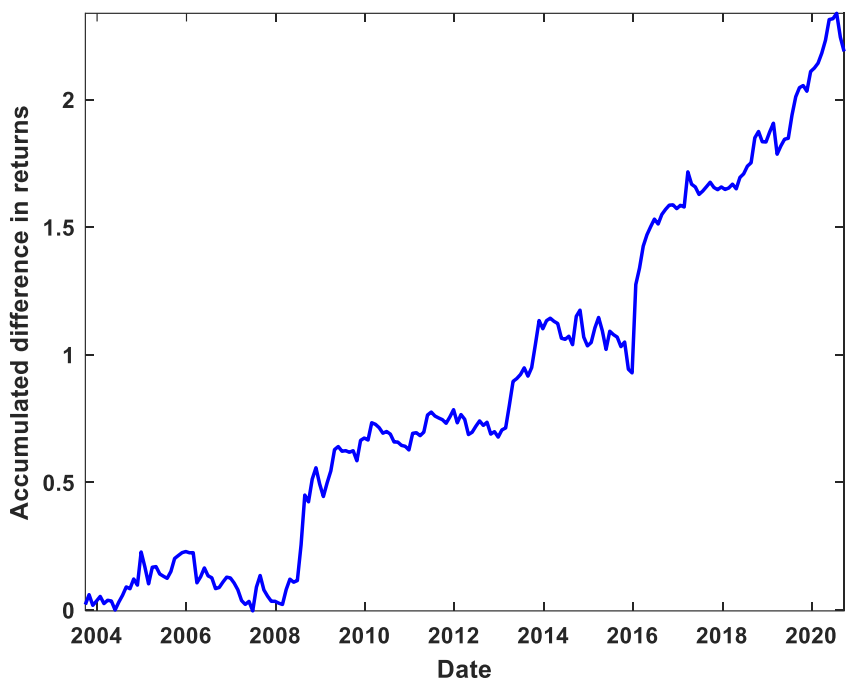

Figure 4. Accumulation of the Difference between the Returns of Simulation Method and Conventional Method (October 2003 - September 2020).

Source: Research findings

We have taken the same approach to compare the two methods in terms of standard deviation $\mathrm{L}=540$ and $\mathrm{f}=18$. We have accumulated differences in the standard deviations of the two methods. ${ }^{1}$ The more this measure decreases over time, the greater the advantage of the simulation method over the conventional one in terms of standard deviation (risk). As presented in Figure (5), from October 2003 to September 2020, the criterion is always negative, which shows the advantage of the simulation method over the conventional one. Moreover, from October 2003 to April 2013, this criterion has always had a downward trend, which shows an increase in the advantage of the simulation method. Although, from April 2013 to September 2020, this criterion has had an upward trend but remained negative, which indicates the persistence of the simulation method outperformance during the entire study period.

\footnotetext{
${ }^{1}$ Considering that 1000 runs have been made for the simulation method in each 18 -days period, for each period the average standard deviation of these 1000 times has been calculated as the standard deviation of the simulation method.
} 


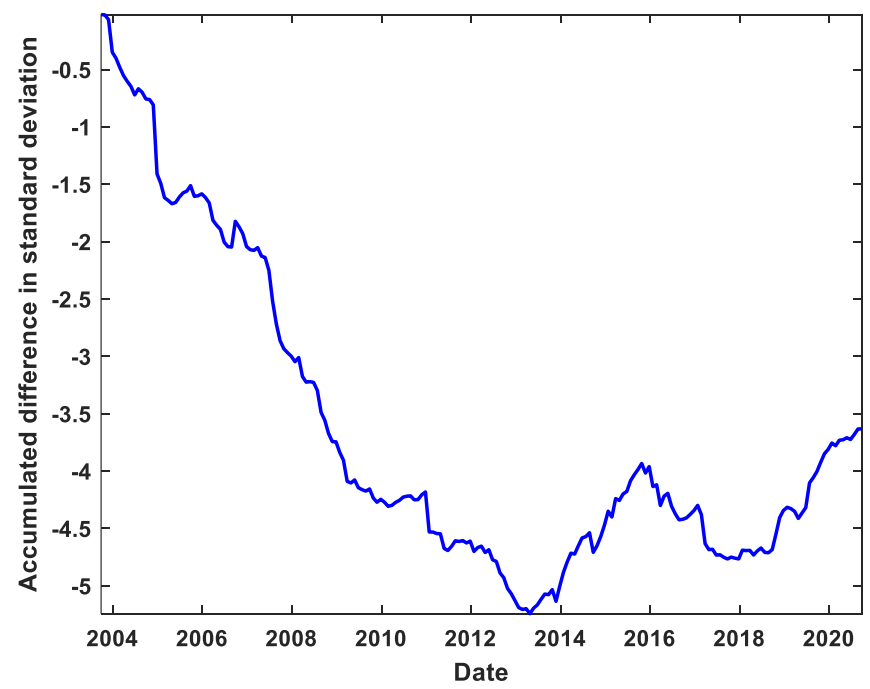

Figure 5. Accumulation of the Difference between the Standard Deviation of Simulation Method and Conventional Method (October 2003 - September 2020). Source: Research findings

Figure (6) plots the performance of two methods in terms of accumulated differences in Sharpe ratios during the same period and the previous assessments. Enhancement of this criterion over time indicates an increase in the advantage of the simulation method based on both returns and standard deviation (Risk) criteria. As Fig. 6 reports, from October 2003 to September 2020 , this criterion has always been positive, showing the simulation method's advantage during the entire study period. In addition, despite the various fluctuations, this criterion has always had an upward trend, which indicates an increase in the advantage of the simulation method over the conventional method in terms of the Sharpe ratio during the period under review. 


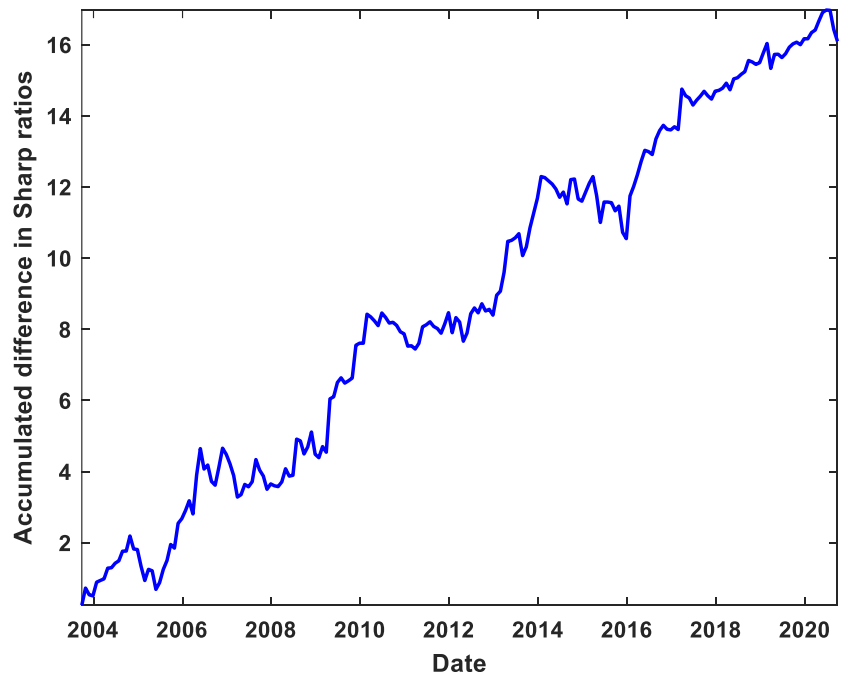

Figure 6. Accumulation of the Difference between the Sharpe Ratios of Simulation Method and Conventional Method (October 2003 - September 2020).

Source: Research findings

To evaluate our results statistically, we use the stochastic dominance test. Accordingly, we work out the empirical cumulative distribution functions (CDFs) for Sharpe ratios derived from the simulation method and conventional one. First, we test the first-order stochastic dominance (FSD), and if the test statistic rejects the FSD, we examine the second-order stochastic dominance (SSD). To this end, we apply the nonparametric McFadden (1989) test (McFadden, 1989). This test assumes that two independent random variables of size $\mathrm{N}$ are distributed between zero and one. The null hypothesis for the first-order stochastic dominance test is:

$H_{0}: F_{1} \leq F_{2} \quad \forall x \in X$

Where $F_{i}$ is the cumulative distribution function of variable $i$. The $\mathrm{H} 0$ hypothesis means that series 1 first-order stochastically dominates series 2 when the CDF of the first series is completely on the right side of the second series CDF. The first-order stochastic dominance test assumes that the investor's utility function is a monotone increasing function and does not make further assumptions. So, no assumptions are made about the curvature of the investors' utility functions in this case. Because the curvature of the utility 
function determines the degree of risk-aversion, FSD results do not depend on the degree of risk aversion of investors.

The variable $x_{1}$ second-order stochastically dominates the variable $x_{2}$, if the following condition holds for all $x \in \mathbb{R}$

$\int_{-\infty}^{x} F_{1}(t) d t \leq \int_{-\infty}^{x} F_{2}(t) d t$

where only part of the cumulative distribution of the variable $x_{1}$ is the right side of the cumulative distribution $x_{2}$ in a way that the above condition holds. In this case, the investor utility function becomes concave, and as a result, investors are risk-averse. Therefore, in the portfolio choice problem, if one portfolio second-order stochastically dominates the other, the risk aversion investors would prefer it. The test statistic defines as

$$
M F_{N}=\sup _{x \in X} \sqrt{N}\left(D_{1,2}(x)\right)
$$

Where $D_{1,2}(x)$ denotes differences between empirical CDFs of two series. Using the above statistic, one can obtain the P-value of the test as follows (Whang, 2019)

$$
P=\exp \left(-2\left(M F_{N}\right)^{2}\right)
$$

Table 4 reports the test $\mathrm{P}$-values for the null hypothesis that the simulation method Sharpe ratio first-order stochastically dominates (FSD) Sharpe ratios of the conventional method and FSD Sharpe ratios of the market portfolios. 
Table 4

$P$-value of first-order stochastic dominance test (McFadden test) simulation over conventional and Market Portfolios

\begin{tabular}{|c|c|c|c|}
\hline Last $L$ Days Used to Form the Portfolio & $\begin{array}{c}540 \\
(2.5 \text { years })\end{array}$ & $\begin{array}{c}1080 \\
(5 \text { years })\end{array}$ & $\begin{array}{c}2160 \\
(10 \text { years })\end{array}$ \\
\hline \multicolumn{4}{|c|}{$f=216$ Days Investment Horizon } \\
\hline Simulation FSD the conventional method & 0.9429 & 0.9355 & 1 \\
\hline $\begin{array}{l}\text { Simulation FSD the market portfolio - using } \\
\text { last } L \text { days info. }\end{array}$ & 0.7903 & 0.5488 & 0.4066 \\
\hline $\begin{array}{l}\text { Simulation FSD the market portfolio - using } \\
\text { last } f \text { days info. }\end{array}$ & 0.9429 & 0.5488 & 0.6703 \\
\hline $\begin{array}{l}\text { Simulation FSD the market portfolio - using } \\
\text { investment day info. }\end{array}$ & 0.9429 & 0.3442 & 0.6703 \\
\hline \multicolumn{4}{|c|}{$f=108$ Days Investment Horizon } \\
\hline Simulation FSD the conventional method & 0.892 & 0.9672 & 0.9512 \\
\hline $\begin{array}{l}\text { Simulation FSD the market portfolio - using } \\
\text { last } L \text { days info. }\end{array}$ & 0.7733 & 0.7408 & 0.8187 \\
\hline $\begin{array}{l}\text { Simulation FSD the market portfolio - using } \\
\text { last } f \text { days info. }\end{array}$ & 0.892 & 0.7408 & 0.8187 \\
\hline $\begin{array}{l}\text { Simulation FSD the market portfolio - using } \\
\text { investment day info. }\end{array}$ & 0.7733 & 0.7408 & 0.6376 \\
\hline \multicolumn{4}{|c|}{$f=54$ Days Investment Horizon } \\
\hline Simulation FSD the conventional method & 1 & 0.9832 & 0.9025 \\
\hline $\begin{array}{l}\text { Simulation FSD the market portfolio - using } \\
\text { last } L \text { days info. }\end{array}$ & 0.8777 & 0.7625 & 0.6635 \\
\hline $\begin{array}{l}\text { Simulation FSD the market portfolio - using } \\
\text { last } f \text { days info. }\end{array}$ & 0.9437 & 0.5433 & 0.7939 \\
\hline $\begin{array}{l}\text { Simulation FSD the market portfolio - using } \\
\text { investment day info. }\end{array}$ & 0.9856 & 0.7625 & 0.7939 \\
\hline
\end{tabular}

The Null Hypothesis: the simulation method Sharpe ratio first stochastically dominates Sharpe ratio of the other method (conventional method or the market Portfolios). If the P-value is not less than 0.05 , the $\boldsymbol{H}_{\mathrm{O}}$ hypothesis will not be rejected at the $5 \%$ significance level.

Source: Research findings

Since all P-values are above $0.34 \%$, the hypothesis will not be rejected at 10,5 , and $1 \%$ significance levels. These results indicate the FSD superiority of the simulation trading strategy over the other ones (conventional method and the market Portfolios), which means the cumulative distribution function of the Sharpe ratio of our method is entirely on the right of the other. In other words, at each level of cumulative distribution, the first investment method's Sharpe ratio is higher. As explained earlier, in the case of FSD, results do not depend on the degree of risk aversion of investors, and as long as investors prefer a higher Sharpe ratio, they would be better off if they followed our proposed strategy.

As no relevant papers were found in the Persian research literature, we refer to the most relevant researches in this field. Considering portfolio 
optimization with the Sharpe ratio maximization method in Iran, Rudposhti et al. (2017) compared the performance of extracted portfolios with Sharpe ratio maximization and Markowitz methods. According to their research, real returns of these two methods are similar, but the risks of the two methods are significantly different.

In the related Persian literature, several papers used the Sharpe ratio to compare the performance of investment portfolios. The approach of these papers is fundamentally different from the Sharpe ratio maximization method because, in the Sharp ratio maximization method, the optimal portfolio is determined in such a way that the Sharpe ratio of that portfolio is maximized, but in the mentioned papers, portfolios are extracted by methods other than Sharpe ratio maximization and to compare their performance, their Sharpe ratio, conditional Sharpe ratio, and other measurements are usually compared. In this regard, we can refer to the studies of Rudpashti \& Mousavi Anzahi (2013), Shaygan Mehr, Zamanian \& Shahiki Tash (2015), and Sabahi, Rafiei \& Rastegar (2015) using Sharpe and other ratios to compare portfolios' performances.

\section{Conclusion}

In this paper, we proposed a new method to perk up the performance of the conventional method in determining the optimal investment portfolio. Unlike the conventional method, our proposed simulation method utilizes a system of simulated MGBM equations in optimal portfolio speculation. To assess the robustness of our findings, the actual market portfolios have been thoroughly investigated for the corresponding periods too. To examine the robustness of the results, we have evaluated its performance for different investment horizons (e.g., seasonally or annually, which is denoted by $f$ ) and various volumes of price information (the number of preceding days used to obtain the optimal portfolio which is denoted by $L$ ) over a long period (approximately twenty years) in the Tehran Stock Exchange (TSE). In doing so, we identified the market portfolios based on the market capitalization of each symbol relative to the total market capitalization using the information of last $L$ and $f$ days, along with information of the investment day (time $t$ ). As far as Sharpe ratio maximization is concerned, the results show that the proposed simulation method performs better than the conventional method and actual market portfolios in all cases. The findings also show that our proposed strategy has a first-order stochastic dominance over the conventional method and market portfolios. Therefore, our results do not depend on the degree of risk aversion of investors. 
Doing further researches needs to be undertaken to see if our findings are related to the fundamental characteristics of the market? And if they can be extended to several other selected stock exchange markets in, for instance, emerging and developed economies. The latter concern is the subject of our next endeavor.

\section{References}

Abensur, E. O., Moreira, D. F., \& De Faria, A. C. R. (2020). Geometric Brownian motion: an alternative to high-frequency trading for small investors. Independent Journal of Management \& Production, 11(3), 1434-1453.

Bachelor, L. (1900) Theory of speculation. Scientific Annals of the École normale supérieure, 17, 21-86.

Back, K. (2010). Asset pricing and portfolio choice theory. Oxford University Press.

Biagini, S., \& Pınar, M. Ç. (2017). The robust Merton problem of an ambiguity averse investor. Mathematics and Financial Economics, 11(1), 1-24. https://doi.org/10.1007/s11579-016-0168-6.

Black, F. and Scholes, M. (1973). The pricing of options and corporate liabilities, Journal of political economy, 81(3), 637-654, 1973. https://doi.org/10.1142/9789814759588_0001.

Buckley, W. S., Brown, G. O., \& Marshall, M. (2012). A mispricing model of stocks under asymmetric information. European Journal of Operational Research, 221(3), 584-592. https://doi.org/10.1016/j.ejor.2012.03.026.

Castellano, R., \& Cerqueti, R. (2012). Optimal consumption/investment problem with light stocks: A mixed continuous-discrete time approach. Applied Mathematics and Computation, 218(12), 6887-6898.

Chellathurai, T., \& Draviam, T. (2007). Dynamic portfolio selection with fixed and/or proportional transaction costs using nonsingular stochastic optimal control theory. Journal of Economic Dynamics and Control, 31(7), 2168-2195..

Chen, W., Zhang, H., Mehlawat, M. K., \& Jia, L. (2021). Mean-variance portfolio optimization using machine learning-based stock price prediction. Applied Soft Computing, 100, 106943. https://doi.org/10.1016/j.asoc.2020.106943.

Cornuejols, G., \& Tütüncü, R. (2006) Optimization methods in finance. Cambridge University Press, 1 st ed.

Dmitrašinović-Vidović, G., \& Ware, A. (2006). Asymptotic behavior of meanquantile efficient portfolios. Finance and Stochastics, 10(4), 529-551. https://doi.org/10.1007/s00780-006-0018-0.

Duffie, D. (2001). Dynamic Asset Pricing Theory. Princeton University Press, 3rd ed. Gambrah, P. S. N., \& Pirvu, T. A. (2014). Risk measures and portfolio optimization. Journal of Risk and Financial Management, 7(3), 113-129. https://doi.org/10.3390/jrfm7030113. 
Kim, W. C., Kim, J. H., \& Fabozzi, F. J. (2015). Robust Equity Portfolio Management, + Website: Formulations, Implementations, and Properties using MATLAB. John Wiley \& Sons (Chapter 3).

Glasserman, P. (2003). Monte Carlo methods in financial engineering: Stochastic Modelling and Applied Probability (3th ed.), 53, Springer Science \& Business Media (Chapter 3).

Kourtis, A. (2016). The Sharpe ratio of estimated efficient portfolios. Finance Research Letters, 17, 72-78.

Lakner, P., \& Ma Nygren, L. (2006). Portfolio optimization with downside constraints. Mathematical Finance: An International Journal of Mathematics, Statistics and Financial Economics, 16(2), 283-299.

Mariani, F., Recchioni, M. C., \& Ciommi, M. (2019). Merton's portfolio problem including market frictions: A closed-form formula supporting the shadow price approach. European Journal of Operational Research, 275(3), 1178-1189. https://doi.org/10.1016/j.ejor.2018.12.022.

Markowitz, H. M. (1952). Portfolio selection, The Journal of Finance, (7)1, 77-91.

Markowitz, H. M. (1959). Portfolio Selection. Efficient Diversification of Investments, John Wiley Sons Ltd.

McFadden, D., (1989). Testing for stochastic dominance, in Studies in the Economics of Uncertainty, edited by T. B. Fomby and T. K. Seo, Springer, ch 7, 113-134.

Merton, R. C. (1971). Optimum consumption and portfolio rules in a continuous time model. Journal of Economic Theory, 3, 373-413. https://doi.org/10.1016/00220531(71)90038-X.

Mwamba, M., \& Mwambi, J. (2010). An alternative to portfolio selection problem beyond Markowitz's: Log Optimal Growth Portfolio. Munich Personal RePEc Archive.

Pedersen, J. L., \& Peskir, G. (2017). Optimal mean-variance portfolio selection. Mathematics and Financial Economics, 11(2), 137-160.

Pun, C. S., \& Wong, H. Y. (2016). Resolution of degeneracy in Merton's portfolio problem. SIAM Journal on Financial Mathematics, 7(1), 786-811. https://doi.org/10.1137/16M1065021.

Rahnama Rudposhti, F., and Nikomram, H., and Tolouei Ashlaghi, A., and Hosseinzadeh Lotfi, F., and Bayat, M. (2017). Evaluate the efficiency of portfolio optimization using the maximum stable Sharpe ratio compared to Markowitz optimization. Financial Management Perspectives, 7 (2 (18)), 125-145. https://www.sid.ir/fa/journal/ViewPaper.aspx?id=305175

Rahnama Rudposhti, F., and Mousavi Anzahi, S. (2013). Comparison of portfolio performance from stock grouping by network model based on new and traditional variables using Sharpe and Treynor indices. Investment Knowledge, 2 (7), 193 212. https://www.sid.ir/fa/journal/ViewPaper.aspx?id=199487

Sabahi, Soodeh and Mofeb Rafiei, Farimah and Rastegar, Mohammad Ali. (2020). Optimizing the investment portfolio with various assets, https://civilica.com/doc/1148843 
Sharpe, W. (1966). Mutual Fund Performance. The Journal of Business, 39(1), 119138. Retrieved August 2, 2021, from http://www.jstor.org/stable/2351741.

Sharpe, W. F. (1994). The Sharpe ratio, Journal of portfolio management, 21(1), 4958.

Shaygan Mehr, A., and Zamanian, G., and Shahiki Tash, M. (2015). Evaluate the performance of mutual funds using stochastic dominance criteria and compare with Sharpe ratio and Sortino ratio. Asset Management and Financing, 3 (4 (11 in a row)), 67-83. https://www.sid.ir/fa/journal/ViewPaper.aspx?id=314668

Spinu, F. (2015). Buy-and-hold versus constantly rebalanced portfolios: A theoretical comparison. Journal of Asset Management, 16(2), 79-84.

Tourin, A., \& Yan, R. (2013). Dynamic pairs trading using the stochastic control approach. Journal of Economic Dynamics and Control, 37(10), 1972-1981. https://doi.org/10.1016/j.jedc.2013.05.010.

Wei, J., \& Wang, T. (2017). Time-consistent mean-variance asset-liability management with random coefficients. Insurance: Mathematics and Economics, 77, 84-96. https://doi.org/10.1016/j.insmatheco.2017.08.011.

Weiner, S. M. (2004). Should Stochastic Volatility Matter to the Cost-Constrained Investor? Mathematical Finance: An International Journal of Mathematics, Statistics and Financial Economics, 14(1), 131-139.

Whang, Y. J., (2019). Econometric analysis of stochastic dominance: concepts, methods, tools, and applications, Cambridge University Press (Chapter2), 32-34.

Xie, S. (2009). Continuous-time mean-variance portfolio selection with liability and regime-switching. Insurance: Mathematics and Economics, 45(1), 148-155. https://doi.org/10.1016/j.insmatheco.2009.05.005.

Xie, S., Li, Z., \& Wang, S. (2008). Continuous-time portfolio selection with liability: Mean-variance model and stochastic LQ approach. Insurance: Mathematics and Economics, 42(3), 943-953. https://doi.org/10.1016/j.insmatheco.2007.10.014.

Yunita, R., Dharmawan, K., \& Harini, L. P. I. (2015). Menentukan portofolio optimal pada pasar saham yang bergerak dengan model gerak brown geometri multidimensi. E-Jurnal Matematika. 4 (3), 127-134.

Zeng, Y., \& Li, Z. (2011). Optimal time-consistent investment and reinsurance policies for mean-variance insurers. Insurance: Mathematics and Economics, 49(1), 145-154. https://doi.org/10.1016/j.insmatheco.2011.01.001. 


\section{Appendix}

Some more detailed outputs:

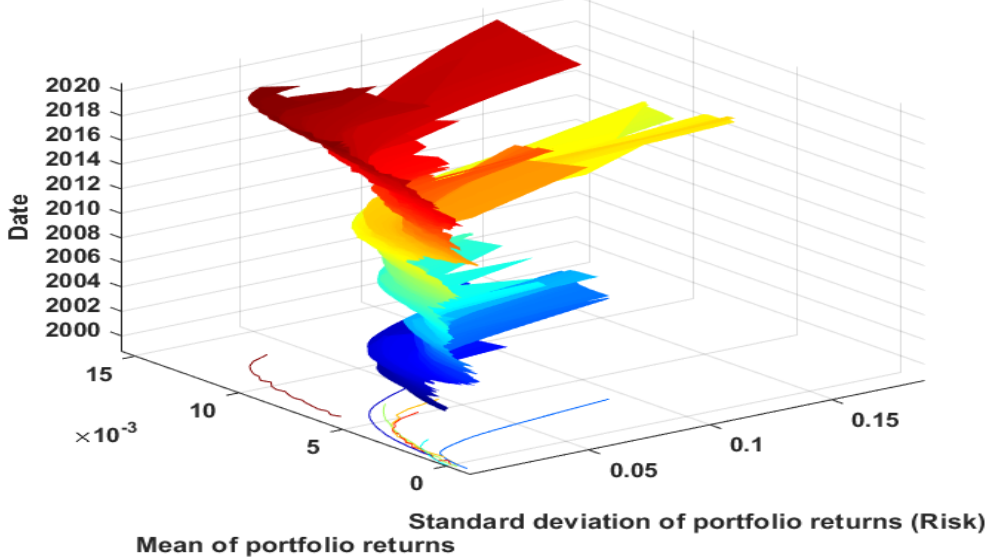

Figure 7. Mean-Variance Efficient Frontier of Conventional Method for 18-Year Period (December 2002 to September 2020) at 1-Month Intervals (18 Trading Days). Source: Research findings

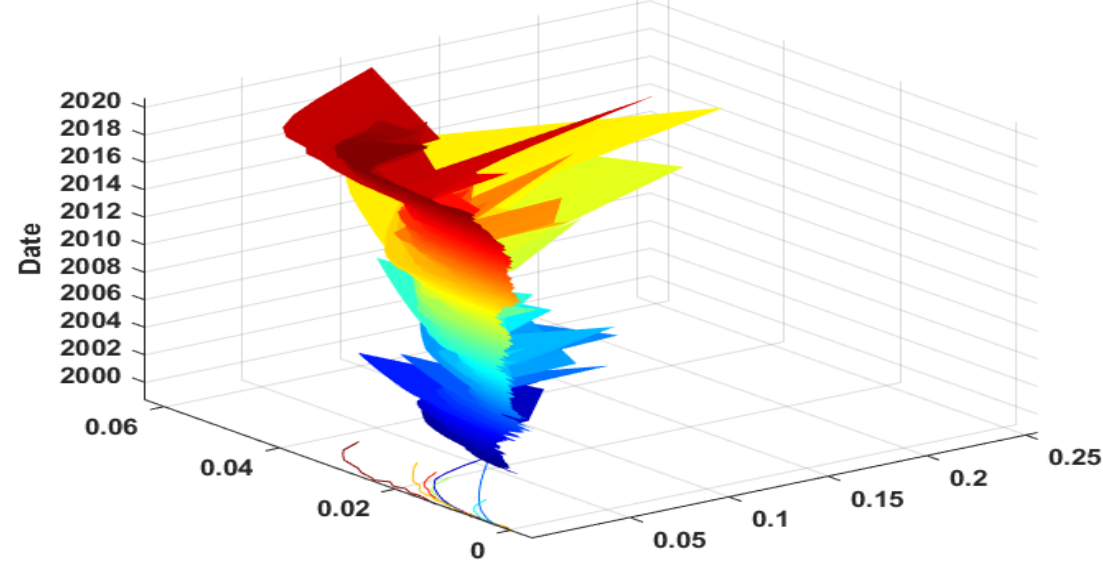

Mean of portfolio returns

Standard deviation of portfolio returns (Risk)

Figure 8. Mean-Variance Efficient Frontier of Simulation Method for 18-Year Period (December 2002 to September 2020) at 1-Month Intervals (18 Trading Days).

Source: Research findings 


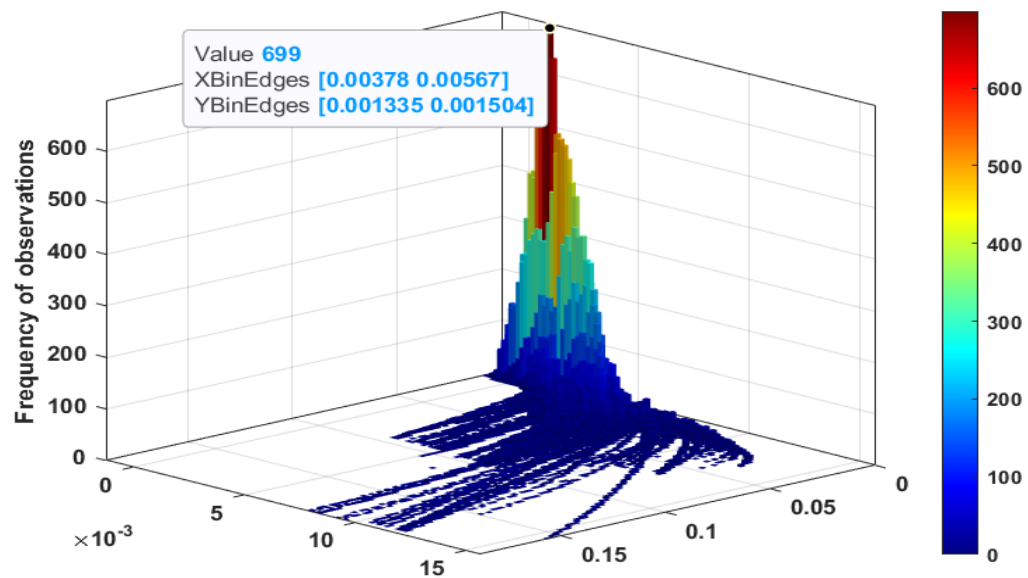

Standard deviation of portfolio returns (Risk)

Mean of portfolio returns

Figure 9. Bivariate Histogram of Conventional Method for 18-Year Period (December 2002 to September 2020) at 1-Month Intervals (18 Trading Days). Source: Research findings

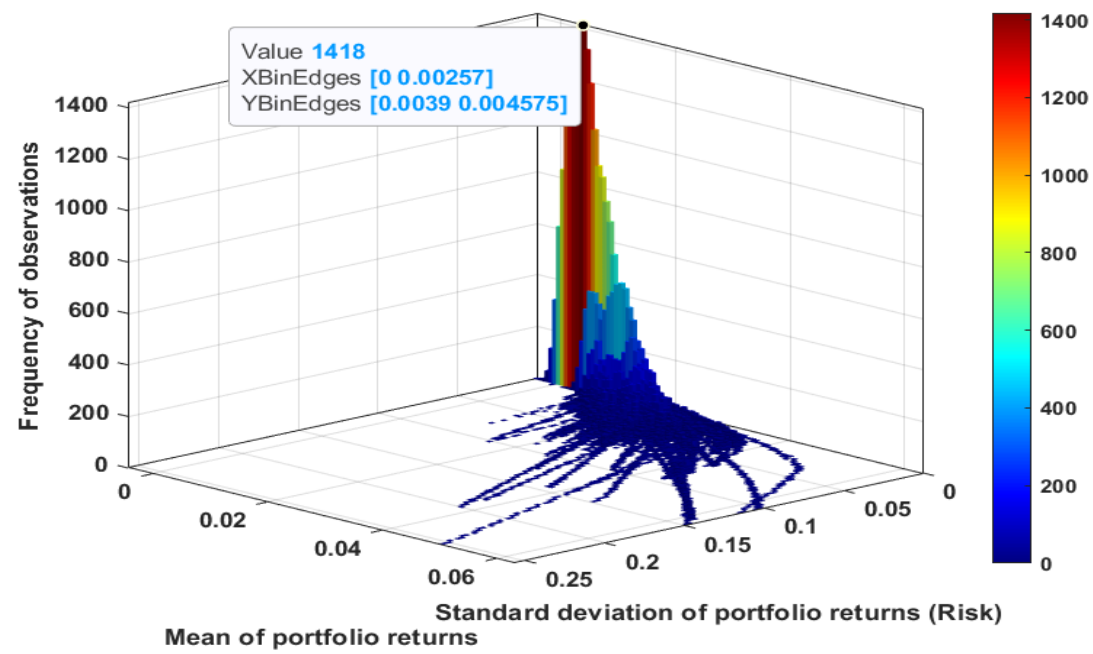

Figure 10. Bivariate Histogram of Simulation Method for 18-Year Period (December 2002 to September 2020) at 1-Month Intervals (18 Trading Days).

Source: Research findings 


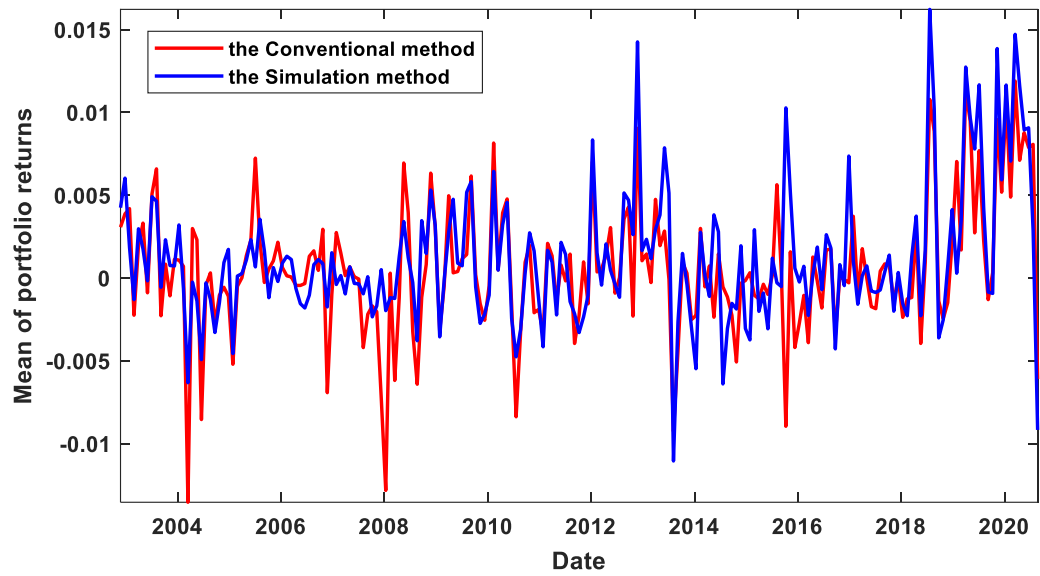

Figure 11. Mean of Portfolio Returns of Conventional (Red) and Simulation (Blue) Methods (October 2003 - September 2020) at 1-Month Intervals (18 Trading Days). Source: Research findings

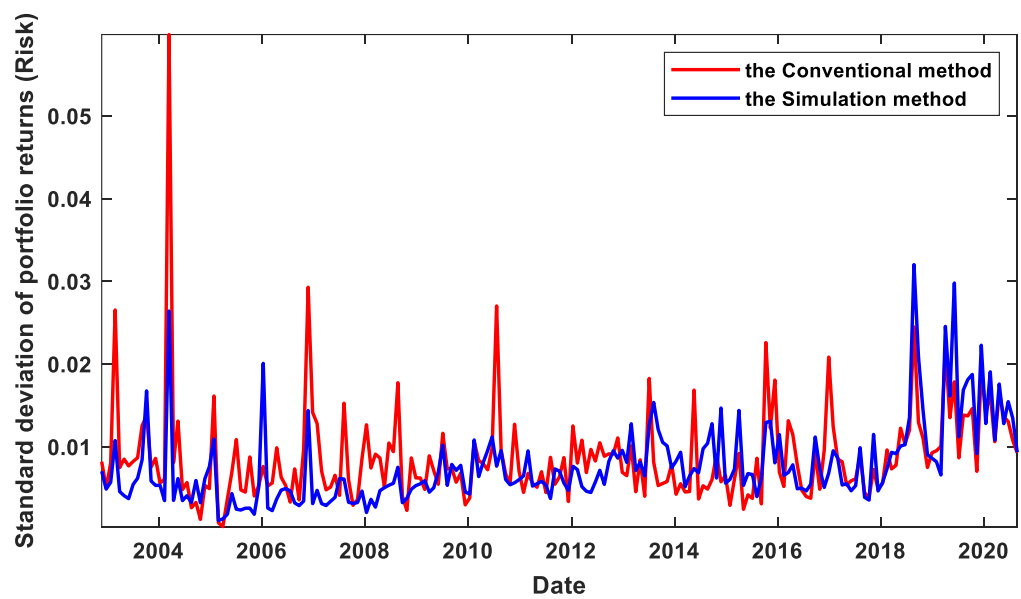

Figure 12. Standard Deviation of Portfolio Returns (Risk) of Conventional (Red) and Simulation (Blue) Methods (October 2003 - September 2020) at 1-Month Intervals (18 Trading Days).

Source: Research findings 


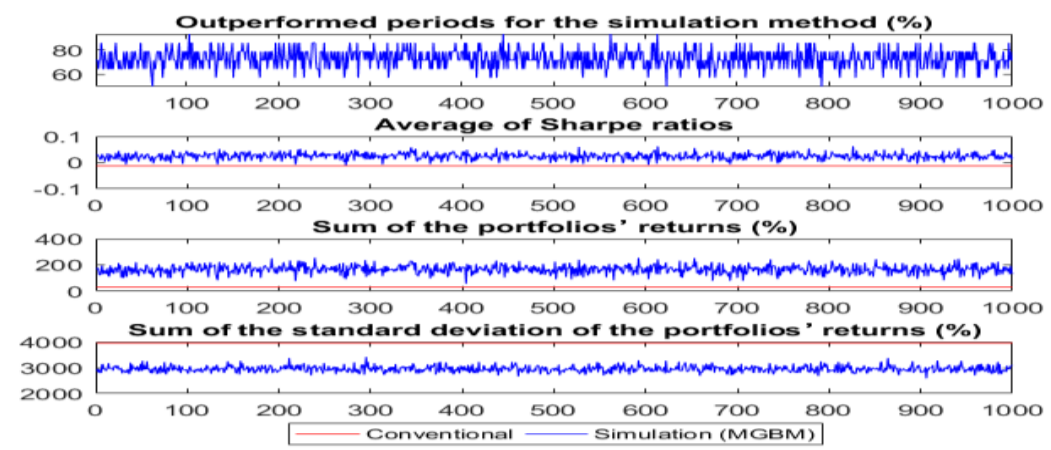

Figure 13. The Performance of Simulation (MGBM) and Conventional Methods for All 1000 Simulation Trials, $\mathrm{L}=1080$ and $\mathrm{f}=216$.

Source: Research findings

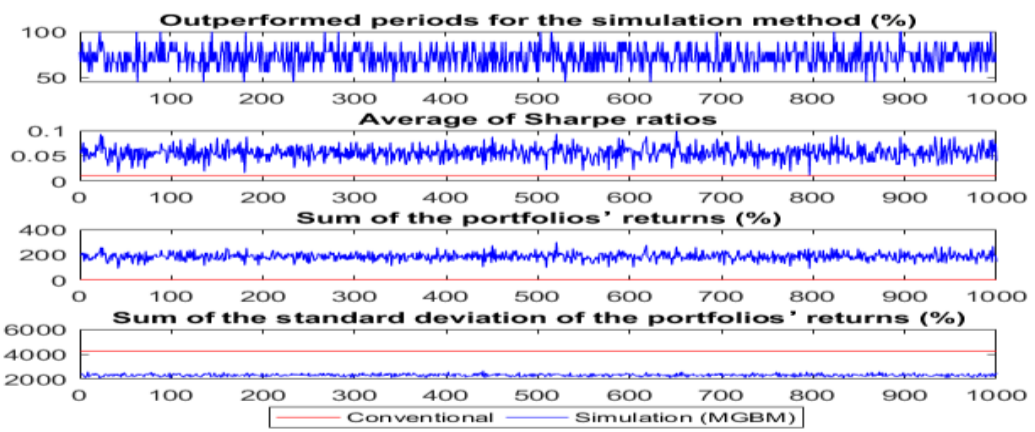

Figure 14. The Performance of Simulation (MGBM) and Conventional Methods for All 1000 Simulation Trials, $\mathrm{L}=2160$ and $\mathrm{f}=216$.

Source: Research findings

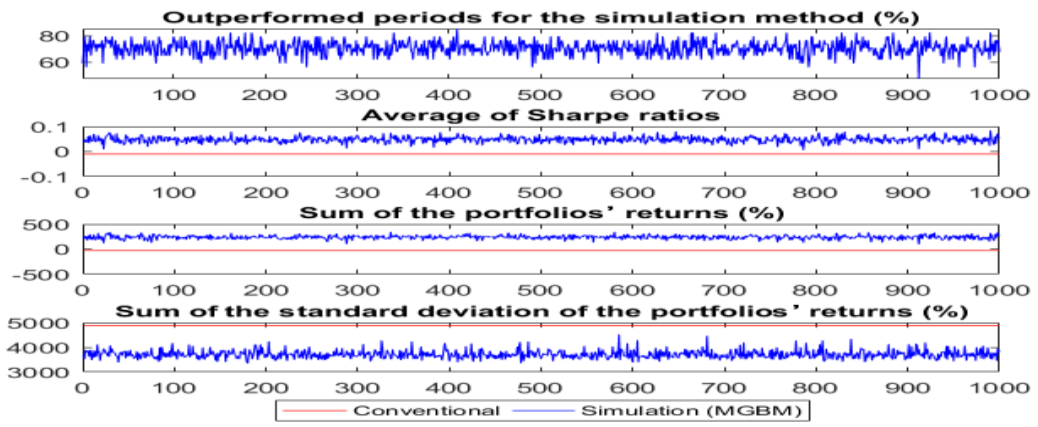

Figure 15. The Performance of Simulation (MGBM) and Conventional Methods for All 1000 Simulation Trials, $\mathrm{L}=540$ and $\mathrm{f}=108$.

Source: Research findings 


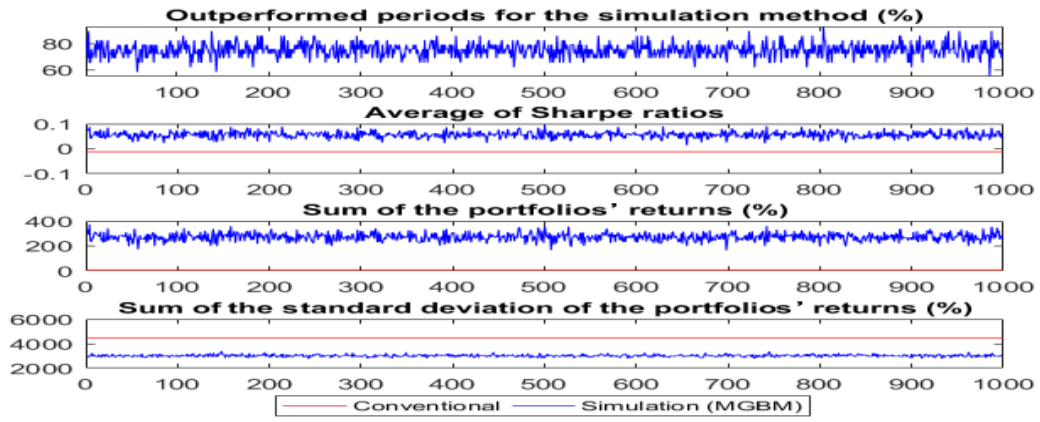

Figure 16. The Performance of Simulation (MGBM) and Conventional Methods for All 1000 Simulation Trials, $L=1080$ and $f=108$.

Source: Research findings

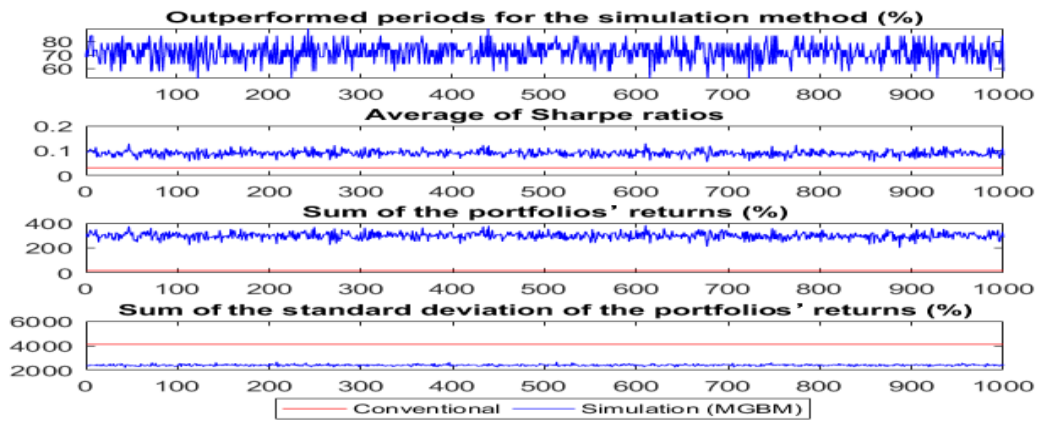

Figure 17. The Performance of Simulation (MGBM) and Conventional Methods for All 1000 Simulation Trials, $\mathrm{L}=2160$ and $\mathrm{f}=108$.

Source: Research findings

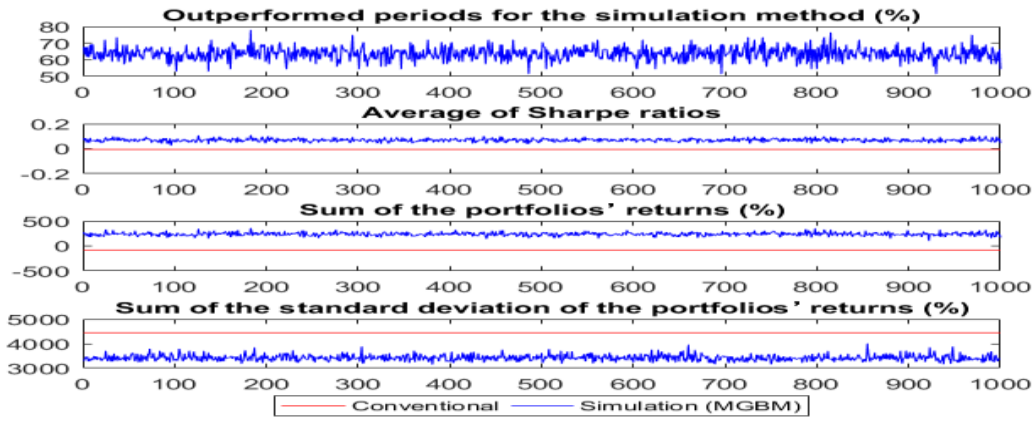

Figure 18. The Performance of Simulation (MGBM) and Conventional Methods for All 1000 Simulation Trials, $\mathrm{L}=540$ and $\mathrm{f}=54$.

Source: Research findings 


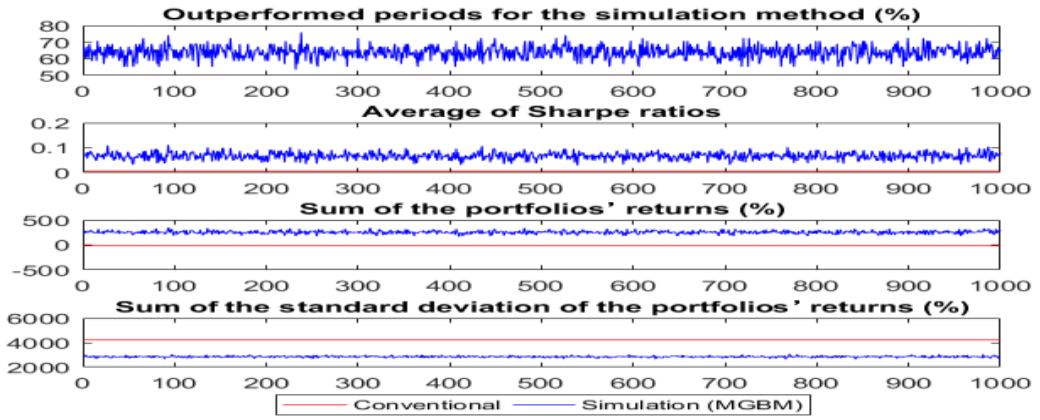

Figure 19. The Performance of Simulation (MGBM) and Conventional Methods for All 1000 Simulation Trials, $\mathrm{L}=1080$ and $\mathrm{f}=54$.

Source: Research findings

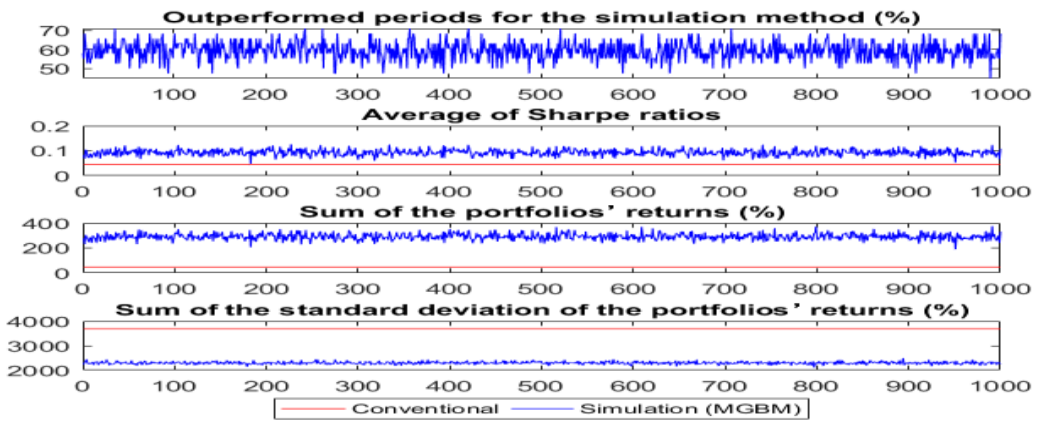

Figure 20. The Performance of Simulation (MGBM) and Conventional Methods for All 1000 Simulation Trials, $L=2160$ and $\mathrm{f}=54$.

Source: Research findings 